\title{
Logistics Facilities Planning and Design Based on SLP
}

\author{
Wu Yujiao", Zhu Lingyao ${ }^{2}$, Wu Yue ${ }^{1}$ \\ ${ }^{1}$ School of logistics, Beijing Wuzi University, Beijing, China \\ ${ }^{2}$ School of Information, Beijing Wuzi University, Beijing, China
}

Email address:

547306488@qq.com (Wu Yujiao),1052992312@qq.com (Zhu Lingyao), wuyue@bwu.edu.cn (Wu Yue)

\section{To cite this article:}

Wu Yujiao, Zhu Lingyao, Wu Yue. Logistics Facilities Planning and Design Based on SLP. American Journal of Applied Scientific Research. Vol. 2, No. 3, 2016, pp. 12-16. doi: 10.11648/j.ajasr.20160203.11

Received: June 6, 2016; Accepted: July 4, 2016; Published: August 4, 2016

\begin{abstract}
In this paper, we analyzed the logistics facility layout of manufacture enterprise based on SLP. By analyzing the functional areas and processes of logistics distribution center, study the relationship between the various operating units. According to the closeness degree of the relationship between operating units determines the distance between the operating units of distance, arrange the position of each working unit. Finally, we evaluated the program and chosen the best program.
\end{abstract}

Keywords: Logistics Facilities Planning, SLP, Program Evaluation

\section{Introduction}

With the rapid development of Chinese economy, logistics distribution and facility planning play an important role in the development of the economy. However, since the development of modern logistics in our China started late, many enterprises only focus on the production to carry out the corresponding planning and design. It leads to the link between the various processes of the enterprise does not meet the requirements of modern logistics, and with some unreasonable reasons in the factory, like a variety of operating cross, alternate transportation, ineffective handling are more serious.

Logistics facilities planning and design are by analyzing the logistics system, flow of people, information flow to make the organic combination and reasonable configuration for buildings, machines, equipment, transport channels and venues etc. So as to achieve the optimization of system internal programming. In China, the layout design of the logistics center is mainly carried out by the designers according to the qualitative analysis. Since the influence of human factors on qualitative analysis is large and the lack of a scientific analysis causes deviations, which bring cost risks for logistics center. It is important to make quantitative analysis for the logistics center's facilities.

\section{Analysis Method of SLP}

In this section, it mainly introduced the concepts and basic steps of SLP.

Basic Concepts of SLP

The basic starting point of SLP is assessing the degree of correlation level between various departments by using the relationship of quantified operation units. Therefore, the primary task of using the SLP method to designing and layout is analyzing the relationship between the operating units, and including quantitative logistics relationship and qualitative non-logistic relationship. Then on the basis of the logistics relationship and non-logistics relationship between the operating units calculates the comprehensive relationship between operating units by weighting method. Finally, express the close degree of comprehensive relationship from high to low in terms of A, E, I, O, U, X and the corresponding score 4, $3,2,1,0,-1$.

The basic steps of the SLP method:

(1) Logistics analysis. The results of the analysis are indicated by the logistics intensity level and the logistics correlation diagram.

(2) Analysis of the relationship between operating units. The results of the non-logistics relationship between operating units are represented by a relational graph.

(3) Determining the importance of the logistics relationship and non-logistics relationship and integrate the logistics correlation diagram and the relational graph of 
operating units to be a comprehensive relation diagram by the weighted method.

(4) The design of the project and the choice of the plan.

\section{Background Analysis of the Enterprise}

An enterprise wants to establish a logistics distribution center. According to the main process route, the distribution center includes nine functional areas: inventory area (A1), loading area (A2), packing area (A3), cold storage area (A4), display area (A5), processing area (A6), distribution area (A7), garbage area (A8) and office area (A9). The main activities of the functional areas as follows:

(1) Inventory area: Storage the production of finished goods or commodities in the daily production and operation of an enterprise.

(2) Loading area: Put the shipping box into the vehicle or into the container.

(3) Packing area: Producing, processing and packaging the products professionally.

(4) Cold storage area: it has an environment automatic monitoring system consists of a computer, a food storage environment monitor, a fan, and other peripheral equipment.

(5) The display area: Display the physical goods and as a media for product introduction and advertising.

(6) The processing area: Processing the products.

(7) Distribution area: Pickup and cargo.

(8) Garbage area: Centralized treatment of wastes.

(9) The office area: garage, air conditioning, elevator, lighting, power supply, shrink, the entire network monitoring for security.

The following table is the details of the distribution center:

Table 1. Factory facilities unidirectional logistics from - to table.

\begin{tabular}{lllllllll|l}
\hline & A1 & A2 & A3 & A4 & A5 & A6 & A7 & A8 & A9 \\
\hline A1 & - & 125 & 425 & 100 & & & & & \\
A2 & & - & & & & & 125 & & \\
A3 & & & - & & 14 & 16 & 225 & & \\
A4 & & & & - & 6 & 25 & 200 & & \\
A5 & & & & & - & & 12 & & \\
A6 & & & 12 & 15 & & - & & 14 & \\
A7 & & & & & & & - & & \\
A8 & & & & & & & & - & \\
A9 & & & & & & & & & - \\
number & 1 & 2 & 3 & 4 & 5 & 6 & 7 & 8 & 9 \\
area & 800 & 400 & 1600 & 800 & 600 & 500 & 800 & 200 & 400 \\
\hline
\end{tabular}

\section{Logistics Facilities Planning Based on SLP}

\section{Step 1: Logistics Analysis}

The first step of optimal design for logistics facilities is to analyze the logistics of the factory. There are 9 areas and we will record the mass flow between each area. Based on the unidirectional logistics from - to table between each area, we can obtain the from-to table of the flow. Then we can calculate the logistics intensity of each unit through this table. Logistics intensity levels and the corresponding scores from high to low are $\mathrm{A}=4, \mathrm{E}=3, \mathrm{I}=2, \mathrm{O}=1, \mathrm{U}=0, \mathrm{X}=-1$. As shown in table 2 .

Table 2. Logistics intensity analysis.

\begin{tabular}{|c|c|c|c|c|c|c|c|c|c|c|}
\hline \multirow{2}{*}{ number } & \multirow{2}{*}{ operating unit group } & \multicolumn{9}{|c|}{ logistics intensity } \\
\hline & & 50 & 100 & 150 & 200 & 250 & 300 & 350 & 400 & 450 \\
\hline 1 & $\mathrm{~A} 1-\mathrm{A} 3$ & & & & & & & & & \\
\hline 2 & A3 - A7 & & & & & & & & & \\
\hline 3 & A4- A7 & & & & & & & & & \\
\hline 4 & $\mathrm{~A} 1-\mathrm{A} 2$ & & & & & & & & & \\
\hline 5 & $\mathrm{~A} 2-\mathrm{A} 7$ & & & & & & & & & \\
\hline 6 & $\mathrm{~A} 1-\mathrm{A} 4$ & & & & & & & & & \\
\hline 7 & A4- A6 & & & & & & & & & \\
\hline 8 & A3-A6 & & & & & & & & & \\
\hline
\end{tabular}

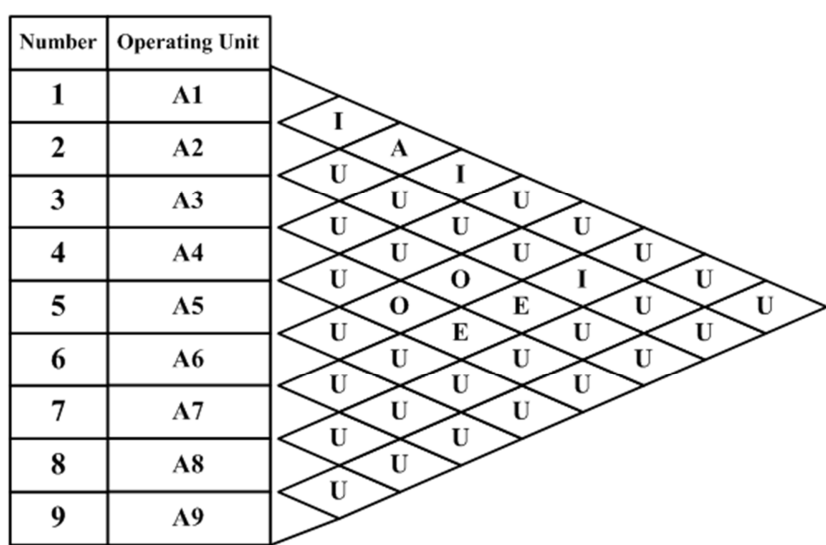

Figure 1. Logistics Relationship Diagram.
As shown in table 2, the specific grade of logistics intensity between the operating units is: A1-A3 is A level; A3-A7 and A4-A7 is E level; A1-A2, A2-A7 and A1-A4 is I grade; $\mathrm{A} 4-\mathrm{A} 6$ and $\mathrm{A} 3-\mathrm{A} 6$ are $\mathrm{O}$ grade.

According to grades of logistics intensity in table 2, we can get the corresponding logistics relationship diagram. As shown in Figure 1.

Step 2: Relationship between operating unit analysis

According to the influence factors of the correlation degree between operating units, the grade of closeness relationship between the various non-logistics operating units can be obtained. Degrees of closeness and corresponding scores from high to low are $\mathrm{A}=4, \mathrm{E}=3, \mathrm{I}=2, \mathrm{O}=1, \mathrm{U}=0, \mathrm{X}=-1$. From the above influence factor, we can get the non-logistics relationship diagram. As shown in Figure 2. 


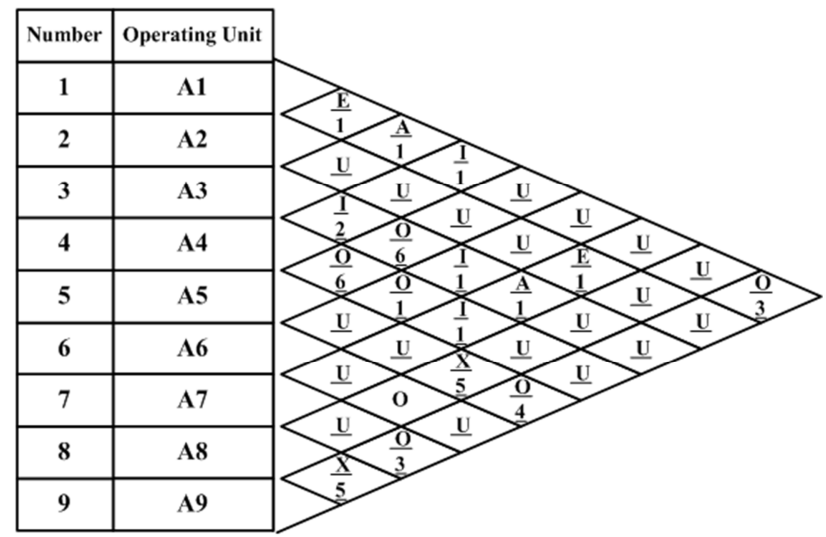

Figure 2. Non-logistics relationship diagram.

Step 3: Determine the level of comprehensive relationship between work units and draw a comprehensive relationship diagram

The weight value of logistics relationship and the non-logistics relationship is equal to 2 and 1, respectively. The values of the degree of closeness are $A=4 E=3 \quad I=2 O=1$ $\mathrm{U}=0 \mathrm{X}=-1$.

The rule of computing the level of a comprehensive relationship: the sum of the double score of logistics relationship and the single score of the relationship between operating unit is the score of the grade of comprehensive relationship.

Then we obtained the integrated score and the grade of each pair of operating units. First pair A1-A3 is A-grade and gets 12 points. Second pair A3-A7 is also A-grade and gets 10 points. Third pair A4-A7 is E-level and gets 8 points. Both A1-A2 and A2-A7 are E-level and get 7 points. Three pairs of operating units A1-A4/A3-A6/A4-A6 are I-grade. Seven pairs of operating units A3-A4/A1-A9、A3-A5、A4-A5、 A5-A9、A6-A8、A7-A9 are O-level. And A1-A5、A1-A6、 A1-A7、A1-A8、A2-A3、A2-A4、A2-A5、A2-A6、A2-A8、 A2-A9、A3-A8、A3-A9、A4-A8、A4-A9、A5-A6、A5-A7、 A6-A7、A6-A9、A7-A8 are all U-level. X-level includes two pairs of operating units A5-A8 and A8-A9. Based on these scores of comprehensive relationship of each pair of working unit, we can set up the working unit comprehensive relationship diagram. As shown in Figure 3.

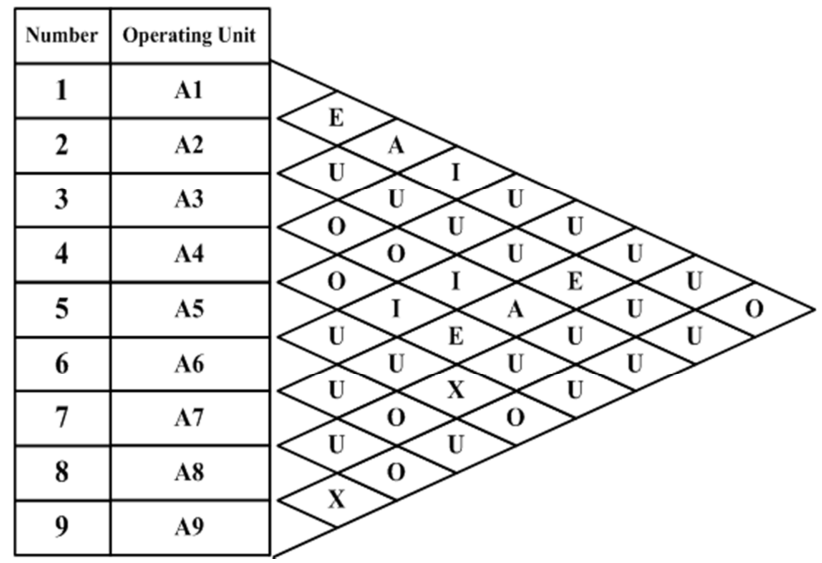

Figure 3. Comprehensive relationship diagram

\section{Step 4: Program design and selection}

According to each functional area size and comprehensive relationship diagrams, it is easy to carry out the program design. Firstly, let three areas A1/A3/A7, which most closely connected and belonged to A-level, are lined up. The goods can take the shortest distance from the storage area to the packaging area, and then to the distribution area. This arrangement can greatly improve work efficiency and save cost. Secondly, design the loading area A2 and the cold storage area A4 separately located above the A-level line and below the A level line. Let A1, A2, A4 and A7 form a rhombus. In this way, the goods can be sent directly to the loading area, when the process from A1 to A3 and to A7 is completed. Besides, cold storage area A4 is closely connected with inventory area $\mathrm{A} 1$, packing area $\mathrm{A} 3$ and distribution area $\mathrm{A} 7$. In the end, the area that has the lower correlation with each other is designed in the outermost ring. They are displayed area $\mathrm{A} 5$, office area $\mathrm{A} 9$, garbage area $\mathrm{A} 8$, and processing area A6 from left to right. At the same time, the garbage area A8 should stay away from the office area A9 and exhibition area A5. As shown in Figure 4 and Figure 5.

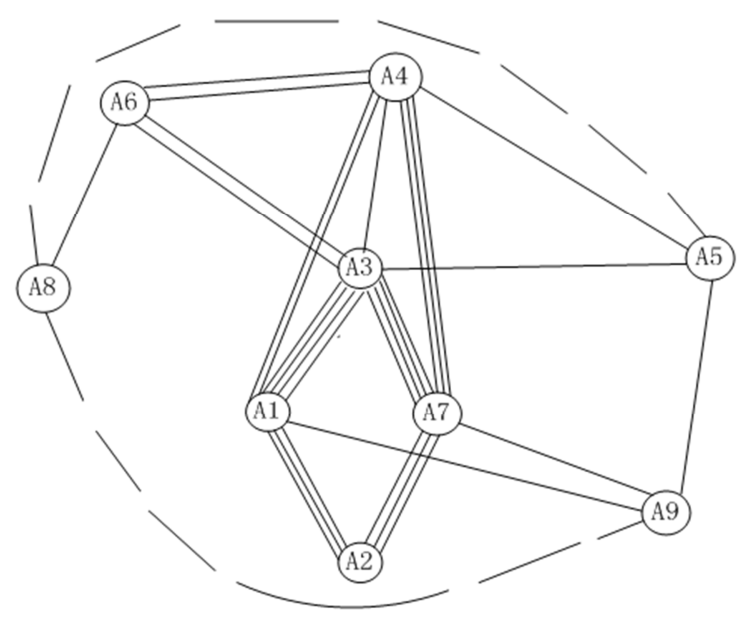

Figure 4. Option 1 of operating unit's location schematic diagram.

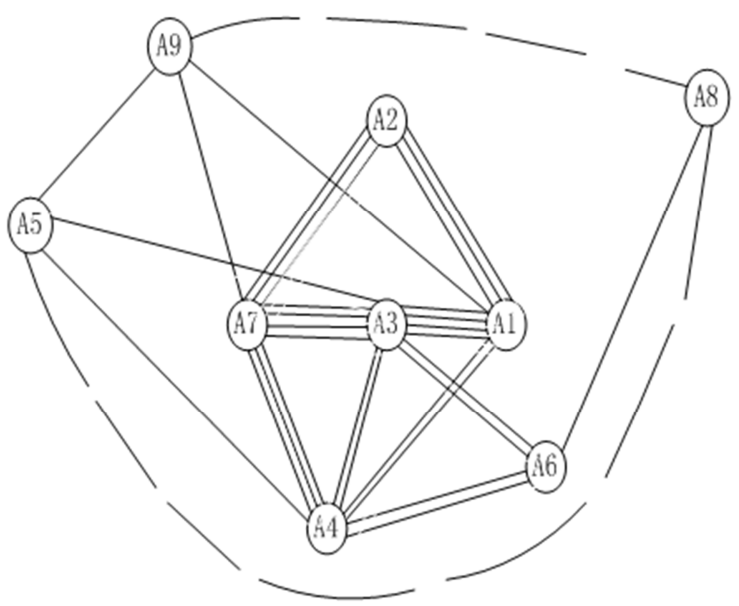

Figure 5. Option 2 of operating unit's location schematic diagram.

Finally, we draw the layout of logistics facilities planning according to the relational chart of operating unit's location. 


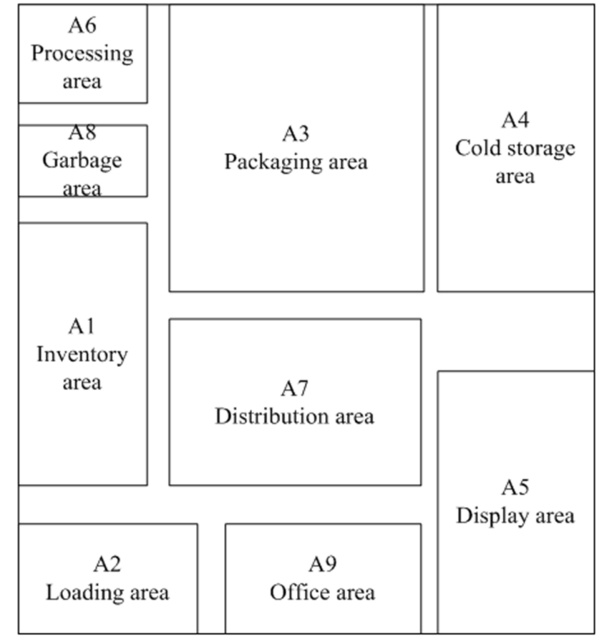

Figure 6. Option 1 logistics facilities layout diagram

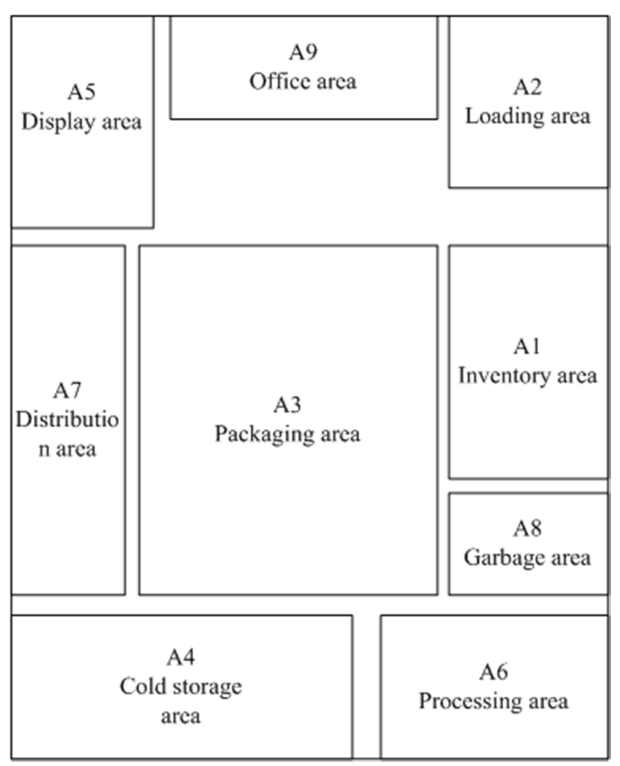

Figure 7. Option 2 logistics facilities layout diagram.

Then we draw distance analysis chart of each unit's flow according to the line distance between each operating unit.

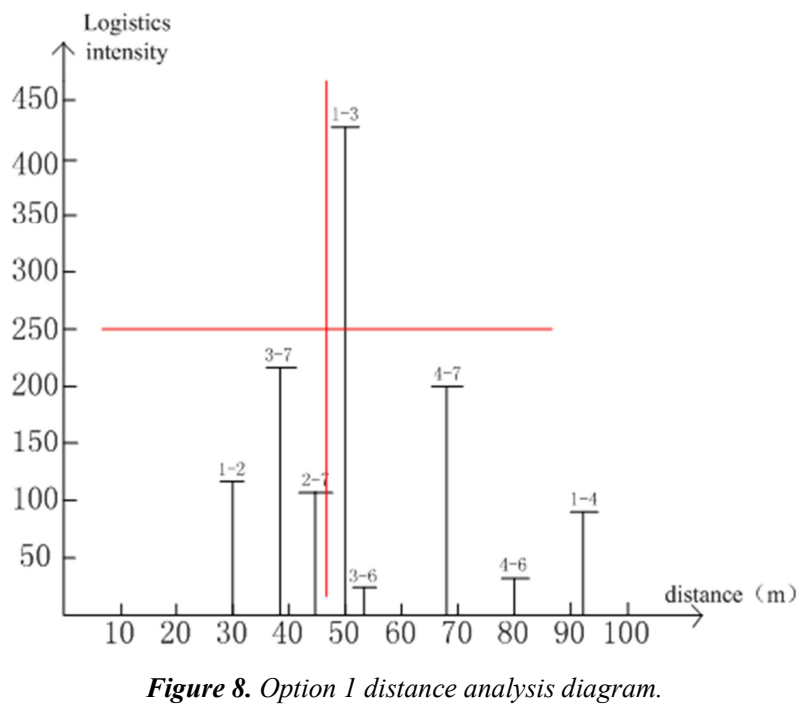

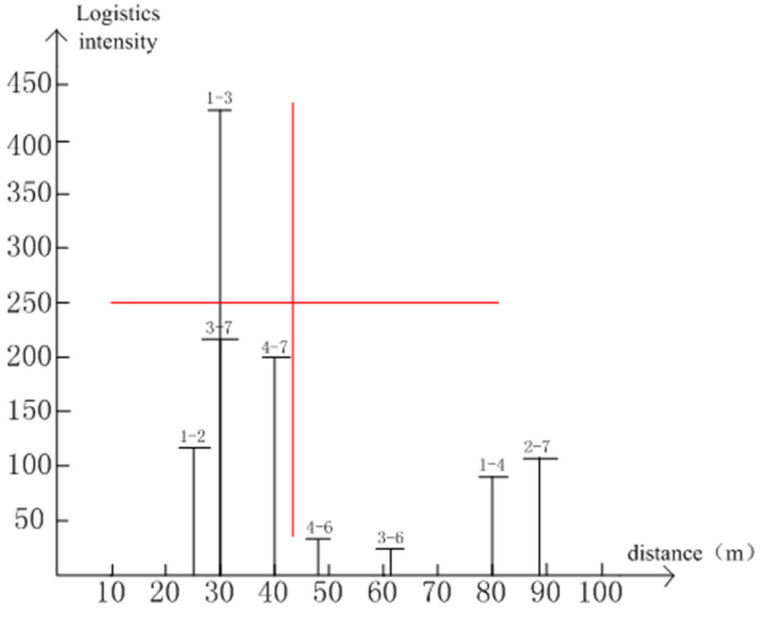

Figure 9. Option 2 distance analysis diagram.

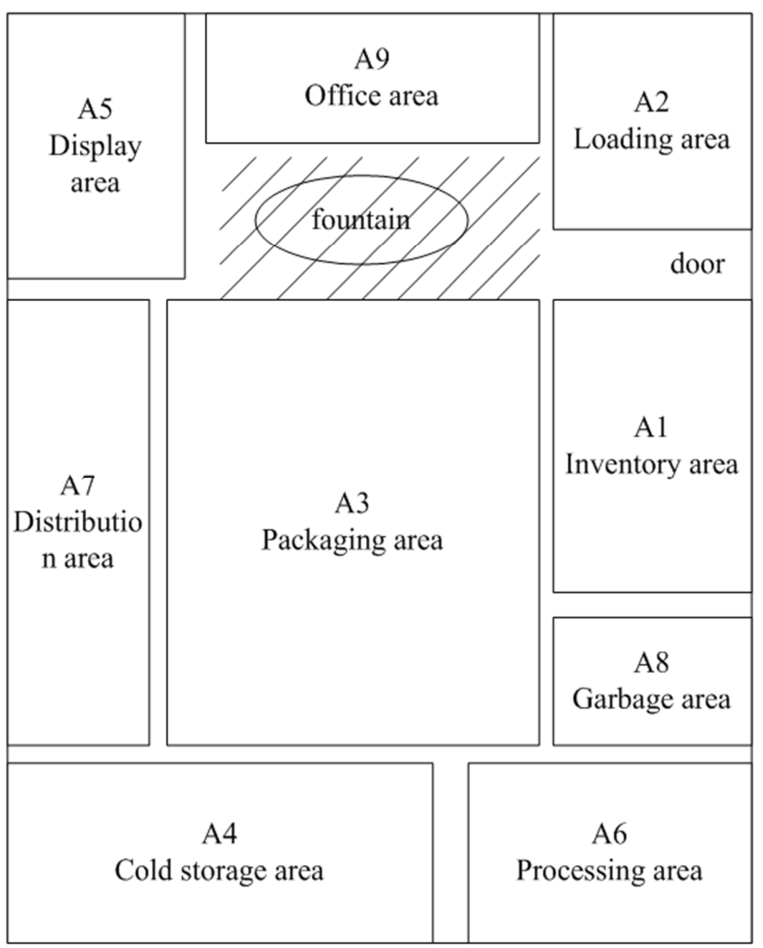

Figure 10. Detailed layout chart of facility.

As can be seen from the figure 9, the area with the largest logistics intensity storage area A1- packing area A3 are in the second quadrant. This can make up for the deficiency of option 1. The rest of the closely related units are also in the third quadrant. It indicates that operating units that have large logistics strength also have smaller distance. Such a layout can truly achieve the goal of saving cost and improving efficiency.

Therefore, we should choose the option 2 as the layout of the plant. And based on the original scheme, the final scheme has more regions and detailed marked. As shown in figure 10.

\section{Conclusion}

In this paper, we selected a plant's logistics facilities planning and design as a case. Through the analysis, we found that the main problem of the plant's layout was the cost of 
waste caused by the distance. We redesigned and decorated the facilities based on SLP logistics facilities planning and proposed two schemes. Finally, we elected the best program through the comparative analysis. After determining the program, we have conducted a detailed layout and made a final decision.

\section{References}

[1] Hao Li, Guiyun Liu. Logistics system planning and design [M]. Zhejiang University Press, 2009:147-167.

[2] Ying Zhang. Research on facility layout of a factory machining workshop based on SLP method [J]. Market Modernization, $2009(32)$

[3] Yan Xiao, Yunkang Cheng, Qiuhong Jia. Application of SLP in plant layout based on low carbon logistics [J]. Energy Materials and Mechanical Engineering Application, 2012:314-317.

[4] Seyedeh Sabereh Hosseini, Kuan Yew Wong, Seyed Ali Mirzapour, Reza Ahmadi. Multi-Floor Facility Layout improvement using Systematic layout planning [J]. Industrial Engineering, 2014:532-537.

[5] Zongxiang Huang, Hao Luo. Study on planning and design of production facility for bearing manufacturing industry based on SLP [J]. System Analysis and Industrial Engineering, 2012:428-432.

[6] Jianhua Yang. A method of layout rearrangement for enterprise logistics system [J]. Engineering Management Information Systems, 2012:446-452.

[7] Chun Wu, Tianjun Hu, Xifu Wang, Chao Zheng. Study on the functional zones layout of fresh food distribution center based on the SLP method [J]. Organization and Management of Modern Manufacturing, 2013 (05).

[8] Haiyao Wang. Application of SLP in the general layout of an Aluminum corporation [J]. Machinery Manufacturing and Automation, 2011 (05).

[9] Taho Yang. Multiple-attribute decision making methods for plant layout design problem[J].Robotics and Computer-Integrated Manufacturing, 2007 , 23(1):126 137.

[10] Alan R. McKendall Jr, Artak Hakobyan. Heuristics for the dynamic facility layout problem with unequal-area departments [J]. European Journal of Operational Research. 2010 201(16):171-182.

[11] Anirban Kundu, Pranab K. Dan. Met aheuristic in facility layout problems: current trend and future direction [J]. International Journal of Industrial and Systems Engineering (IJISE),2012 10(2):238-253 